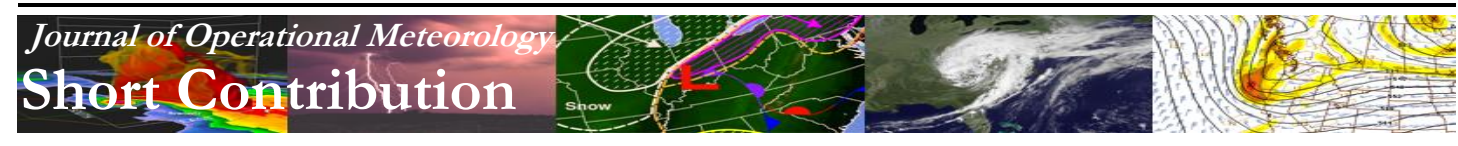

\title{
Observations and Operational Considerations of the 4 June 2013 Chaff Event in Northern Alabama
}

\author{
TODD A. MURPHY \\ University of Louisiana at Monroe, Monroe, Louisiana \\ RYAN A. WADE \\ University of Alabama at Huntsville, Huntsville, Alabama \\ BRIAN C. CARCIONE \\ National Weather Service, Huntsville, Alabama
}

(Manuscript received 23 August 2015; review completed 24 November 2015)

\begin{abstract}
On 4 June 2013, a military chaff release occurred near Huntsville, Alabama, within the University of Alabama in Huntsville (UAH) mesoscale network. This event was unusual because the chaff remained in the atmosphere - maintaining a radar echo on nearby weather radars - for nearly $10 \mathrm{~h}$ after the initial release. This paper examines the radar evolution of the chaff event, supplemented by environmental observations using the UAH profiling equipment. Additionally, unique operational considerations faced by the National Weather Service Weather Forecast Office in Huntsville are addressed.
\end{abstract}

\section{Introduction}

Chaff is composed of small, aluminum-coated, silica core strands and is known for its highly reflective properties in the microwave part of the electromagnetic spectrum [United States Air Force (USAF) 1997]. It is used as an aircraft radar countermeasure and commonly appears on weather radars located near military bases during training exercises. One such chaff release occurred at approximately 1830 UTC 4 June 2013 near Huntsville, Alabama, during a military exercise at the United States Army Redstone Arsenal (RSA). Similar to other chaff releases, this event showed prominently on nearby weather radars, such as the National Weather Service (NWS) Weather Surveillance Radar-1988 Doppler (WSR-88D) located in Hytop, Alabama (KHTX, Fig. 1), equipped with dualpolarization capability. However, unlike numerous well-documented examples seen across the WSR-88D network prior to this event, this chaff release was unusual in that the chaff lingered in the atmosphere for nearly $10 \mathrm{~h}$, maintaining a radar echo until just after 0430 UTC 5 June 2013. Under typical conditions, chaff will remain in the atmosphere for $2-5 \mathrm{~h}$ (USAF 2010).

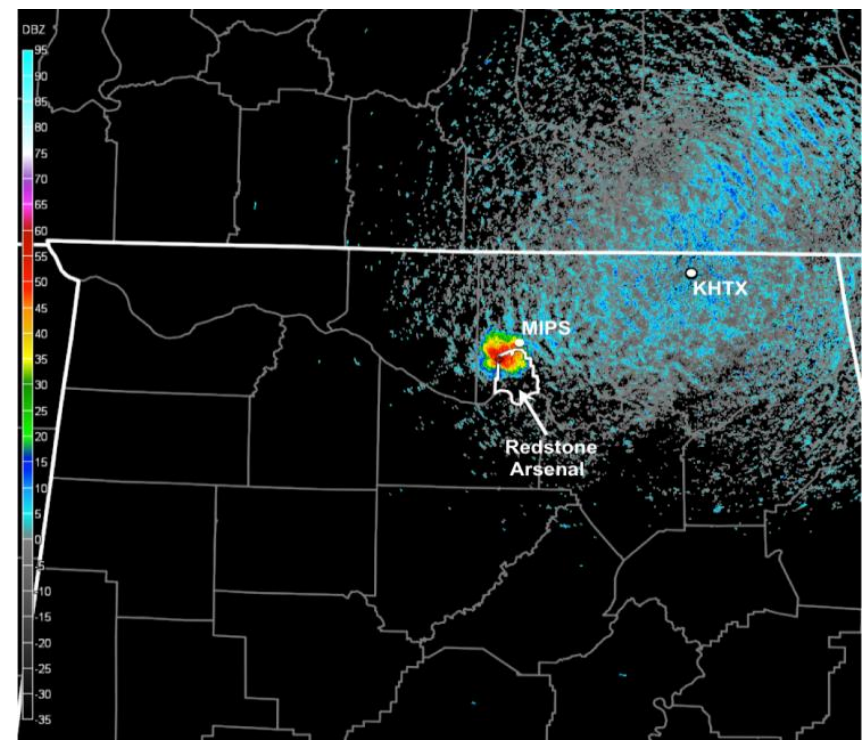

Figure 1. $0.5^{\circ}$ base reflectivity from KHTX valid 1957 UTC 4 June 2013, about $90 \mathrm{~min}$ after the initial chaff release. Maximum reflectivity was $62.5 \mathrm{dBZ}$. Relative locations of the KHTX radar and profiling instruments at the MIPS site located at UAH are indicated with white markers. The red cross-hair marker within the chaff radar echo indicates the point source location for the initial radar echo associated with the chaff release. Redstone Arsenal is outlined in white here and in subsequent radar figures. Click image for an external version; this applies to all figures hereafter.

Corresponding author address: Todd A. Murphy, University of Louisiana at Monroe, 700 University Ave, Monroe, LA 71209 
Chaff fibers from RR-188, one of the many forms of chaff, are extremely small [length $=0.76-2.54 \mathrm{~cm}$ $(0.3-1 \mathrm{in})$; diameter $=25.4 \mu \mathrm{m})$ and light so that they remain in the air long enough to confuse human interpretation or computer algorithms of aircraft-tracking radar before drifting to the ground. A single RR-188 cartridge contains approximately 5.46 million fibers, that when released, initially occupies a spherical volume before dispersing (USAF 1997). Examples of chaff fibers from this event are shown in Fig. 2.

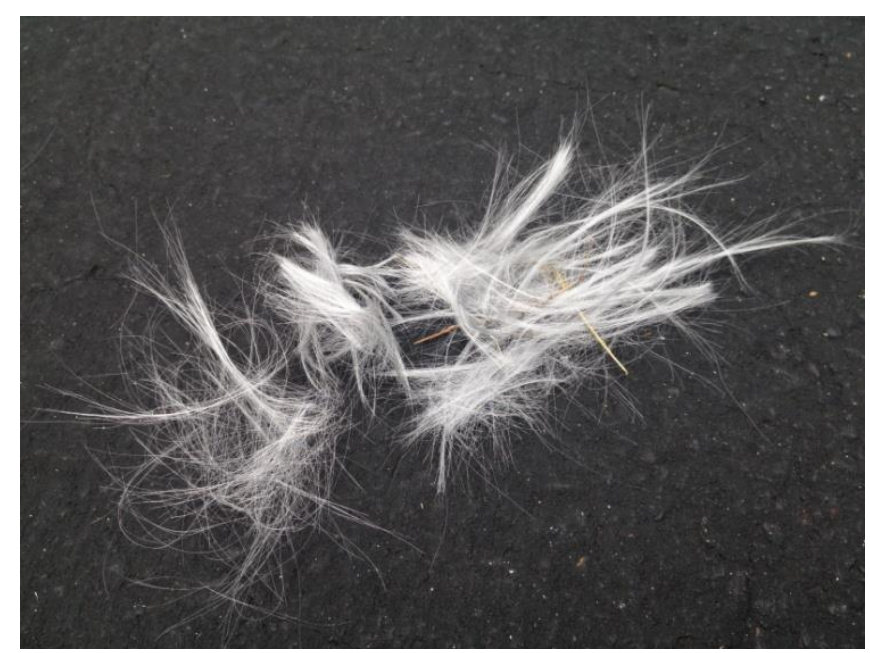

Figure 2. Clumps of chaff fibers collected by R. Wade and T. Murphy near the initial radar echo point source indicated in Fig. 1.

Radar chaff used to study clear-air convection has a fall speed between 0.33 and $1.67 \mathrm{~m} \mathrm{~s}^{-1}$ (e.g., Rowland 1976). Chaff may be lofted if released into a convective thermal with vertical motions exceeding this fall speed. Clear-air convection caused the chaff studied by Rowland to rise rapidly to the top of the convective boundary layer (CBL). The volume occupied by the chaff spread out spherically and increased in size by $25-50 \%$. The chaff "bubbles" drifted with the background wind for up to $30 \mathrm{~min}$ before dissipating. Radar returns from chaff may interfere with radar precipitation estimation (e.g., Vasiloff and Struthwolf 1997) or even become embedded in precipitation and enhance radar returns (e.g., Brandt and Atkin 1998). Han et al. (2011) showed reflectivity factor at horizontal polarization $(Z)$ of initial point echoes from a chaff release might approach $30-50 \mathrm{dBZ}$ before diffusing to $<30 \mathrm{dBZ}$ within a matter of minutes.

Zrnić and Ryzhkov (2004) examined polarimetric properties of a chaff event in Oklahoma, noting $Z<30$ $\mathrm{dBZ}$, differential reflectivity $\left(Z_{\mathrm{DR}}\right)$ of $0-6 \mathrm{~dB}$, and correlation coefficient $\left(\rho_{\text {hv }}\right)$ of $0.2-0.5$. However, these were measured after the chaff had drifted into southern Oklahoma, diffusing from its release location in eastern New Mexico. For comparison with precipitation, $Z_{\mathrm{DR}}$ can occupy a wide range of values because it is shape dependent. However, $\rho_{\mathrm{hv}}$ is best for discriminating between chaff and precipitation because it is $>0.98$ in rain, $>0.6-0.8$ in melting snow, and typically $>0.8$ in hail (Zrnić and Ryzhkov 2004; Kumjian 2013a).

The chaff release on 4 June 2013 occurred within the northern Alabama mesoscale network (described in section 2), allowing for a high-resolution temporal examination of the boundary layer for the event's duration. This paper's primary purpose is to detail the radar evolution of the chaff and explore why it remained in the atmosphere well after its initial release. Given increased public awareness and use of common meteorological tools, such as weather radar, the chaff release garnered much media and public attention in northern Alabama (e.g., Gattis 2013; Gore 2013a,b; Roop 2013; WHNT 2013). This was exacerbated by RSA's initial reluctance to confirm the chaff release as the source of the radar echo and the fact that radar-observed chaff echoes are uncommon near RSA (Gattis 2013). The unusual nature of the event presented unique operational challenges for the NWS Weather Forecast Office (WFO) in Huntsville, and this paper will outline those issues.

\section{Data and methods}

The data for this study are derived from a subset of instruments within the northern Alabama mesoscale network ${ }^{1}$ - the University of Alabama in Huntsville (UAH) Mobile Integrated Profiling System (MIPS; Karan and Knupp 2009) and KHTX radar. Figure 1 shows the relative locations of these instruments in northern Alabama. KHTX radar data were evaluated in the Gibson Ridge software program, GRLevel2 Analyst (GR2A), and precipitation data were evaluated using the National Oceanic and Atmospheric Administration (NOAA) Weather and Climate Toolkit. The chaff's radar evolution was largely assessed using $Z$; however, the polarimetric variables $Z_{\mathrm{DR}}$ and $\rho_{\mathrm{hv}}$ were compared to previous radar chaff studies. Precipitation data were assessed using 1-h total and storm-total precipitation from both legacy (i.e., based on $Z$ ) and polarimetric (based on combinations of $\mathrm{Z}$ and $Z_{\mathrm{DR}}$ ) al-

\footnotetext{
1 The Advanced Radar for Meteorological and Operational Research (ARMOR) polarimetric C-band Doppler radar and the Mobile Alabama X-band (MAX) polarimetric Doppler radar were not operational during this event.
} 
Table 1. MIPS instrument specifications.

\begin{tabular}{|c|c|c|c|c|c|}
\hline Instrument & Quantities Measured or Calculated & $\begin{array}{l}\text { Measurement } \\
\text { Height }\end{array}$ & $\begin{array}{c}\text { Vertical } \\
\text { Resolution }\end{array}$ & $\begin{array}{l}\text { Temporal } \\
\text { Resolution }\end{array}$ & $\begin{array}{c}\text { Dwell } \\
\text { Time }\end{array}$ \\
\hline $\begin{array}{l}915-\mathrm{MHz} \\
\text { profiler }\end{array}$ & $\begin{array}{l}\text { Signal-to-noise ratio, vertical velocity, spectral width, } \\
\text { horizontal wind, Doppler velocity spectra }\end{array}$ & $0.12-4 \mathrm{~km}$ & $105 \mathrm{~m}$ & $60 \mathrm{~s}$ & $30 \mathrm{~s}$ \\
\hline Ceilometer & Two-way backscatter, cloud base & $0.03-15 \mathrm{~km}$ & $10 \mathrm{~m}$ & $15 \mathrm{~s}$ & $15 \mathrm{~s}$ \\
\hline
\end{tabular}

gorithms (Berkowitz et al. 2013). The MIPS instruments used for this study include a 915-MHz Doppler wind profiler and a lidar ceilometer. The MIPS operated from its "home base" location on the UAH campus. Summaries of the MIPS instrument specifications used in this study are given in Table 1.

The MIPS allowed for a temporal evaluation of atmospheric conditions for the duration of the chaff event. The $915-\mathrm{MHz}$ Doppler wind profiler is primarily a boundary layer radar sensitive to Bragg scatter such that the height of the returned signal is dependent on water vapor concentration, atmospheric stability, and turbulent mixing processes. Its data were averaged over $30 \mathrm{~min}$ to produce consensus wind profiles using the National Center for Atmospheric Research Improved Moments Algorithm (NIMA) software (Cornman et al. 1998; Morse et al. 2002). The evolution of the background boundary layer wind was evaluated with the NIMA wind profiles. Raw 915-MHz 1-min spectral data of signal-to-noise ratio (SNR), radial velocity $\left(V_{R}\right)$, and spectral width $(S W)$ were used to characterize the boundary layer evolution, timing of the chaff drift over the MIPS site, backscatter return from the chaff, and thermal updraft lofting of chaff. The $915-\mathrm{MHz} V_{R}$ data represent vertical particle motion $(W)$, where $W=$ air motion $(w)+$ particle terminal fall velocity $\left(V_{T}\right)$, when assuming that Rayleigh scattering of chaff fibers dominates over the Bragg scattering of vertical variations in temperature, water vapor, and turbulence. The lidar ceilometer measures vertical profiles of aerosol backscatter at 15-s temporal resolution and $10-\mathrm{m}$ gate spacing. The ceilometer data were used to estimate the CBL height during the chaff release (e.g., Eresmaa et al. 2012).

\section{Analysis and discussion}

\section{a. Radar and environment analysis}

At approximately 1836 UTC 4 June 2013, a $Z$ point source of $\angle 15 \mathrm{dBZ}$ appeared on KHTX at $0.5^{\circ}$ elevation (near $0.8 \mathrm{~km}$ AGL) $65 \mathrm{~km}$ west-southwest of the radar and $8.4 \mathrm{~km}$ west-southwest of the MIPS, near the northwestern most corner of RSA (Fig. 3a). The $Z$ echo quickly expanded in a circular shape while increasing in magnitude, similar to other clear-air chaff releases (e.g., Rowland 1976). At 1934 UTC, about an hour after the initial release, the chaff's $Z$ echo expanded to a diameter near $11 \mathrm{~km}$ and a spatial maximum $Z\left(Z_{\max }\right)>55 \mathrm{dBZ}$ (Fig. 3b), reminiscent of a strong airmass thunderstorm. At 2015 UTC, a second $Z$ point source appeared on KHTX at $0.5^{\circ}$ elevation (near $0.9 \mathrm{~km} \mathrm{AGL}$ ), approximately $5 \mathrm{~km}$ due south of the original $Z$ point release, and still within the RSA border. The second $Z$ region also quickly expanded, merging with the larger original $Z$ region to the north, while preferentially expanding eastward across RSA (Figs. 3c and 3d). When viewed as a radar animation (Fig. 3 animation), this second chaff release has the appearance of gust-front convective redevelopment along the southern flank of a thunderstorm. The nowcombined high-reflectivity core with values of $Z_{\max }$ $\geq 55 \mathrm{dBZ}$ continued to appear on KHTX at $0.5^{\circ}$ until 2133 UTC (Fig. 3d), while $Z_{\max } \geq 50 \mathrm{dBZ}$ lasted until 2358 UTC, after which $Z$ values slowly decreased as the chaff gradually diffused in the atmosphere (Figs. $3 \mathrm{e}$ and $3 \mathrm{f}$ ). The maximum spatial $Z_{\max }$ for the event's duration was $64.5 \mathrm{dBZ}$ at 2003 UTC, nearly $90 \mathrm{~min}$ utes after the initial release. This is unique because $Z$ typically peaks soon after release before gradually decreasing. The extended period of $Z_{\max }>50 \mathrm{dBZ}$ is also unusual for a clear-air chaff release (e.g., Rowland 1976; Han et al. 2011) and likely indicative of weak boundary layer winds causing a slow diffusion rate of the chaff fibers. This is confirmed by a timeheight section of winds derived from the $915-\mathrm{MHz}$ profiler (Fig. 4) that generally shows weak $\left(\leq 3.6 \mathrm{~m} \mathrm{~s}^{-1}\right.$ or $<7 \mathrm{kt}$ ) and variable winds below $1.5 \mathrm{~km}$ AGL from the time of the chaff release until 0200-0300 UTC 5 June 2013.

By 0000 UTC 5 June 2013, the chaff's radar appearance was ragged and ill-defined, losing its circular shape (Fig. 3e). However, $Z_{\max } \geq 30 \mathrm{dBZ}$ continued for several more hours, indicating a persistent high concentration of chaff fibers. This would last until 0230-0330 UTC, when $Z_{\max }$ decreased to $<30 \mathrm{dBZ}$ and the chaff's $Z$ echo drifted west and finally westnorthwest into Tennessee and out of the northern Alabama mesoscale network (Fig. 3f). The decreased $Z$ and westward motion of the radar echo was coincident with an increase in east to east-southeast winds 

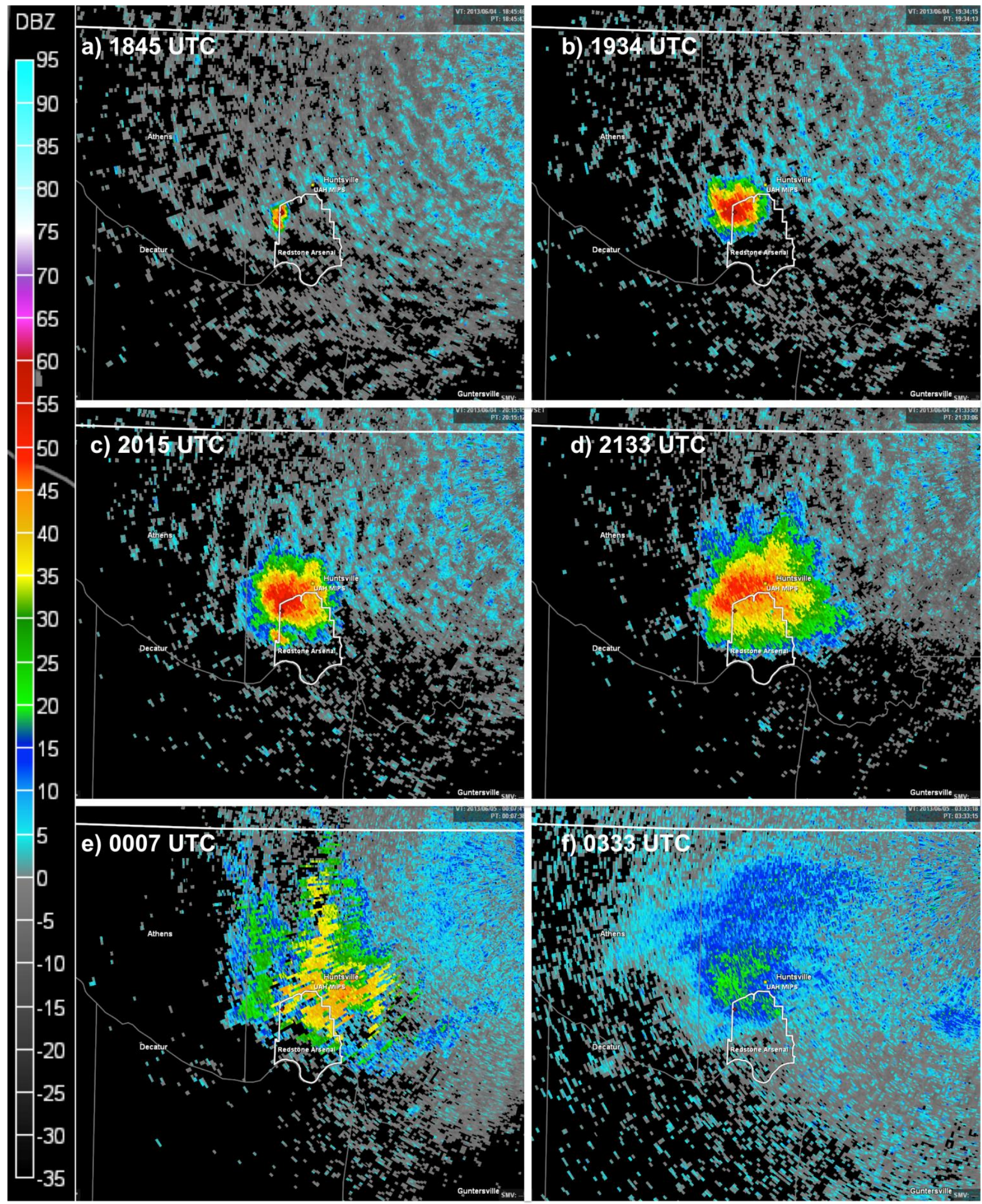

Figure 3. $0.5^{\circ}$ base reflectivity from KHTX valid (a) 1845 UTC, (b) 1934 UTC, (c) 2015 UTC, (d) 2133, (e) 0007 UTC, and (f) 0333 UTC 4-5 June 2013. Click image for an animation from 1807 UTC 4 June 2013 to 0530 UTC 5 June 2013. 


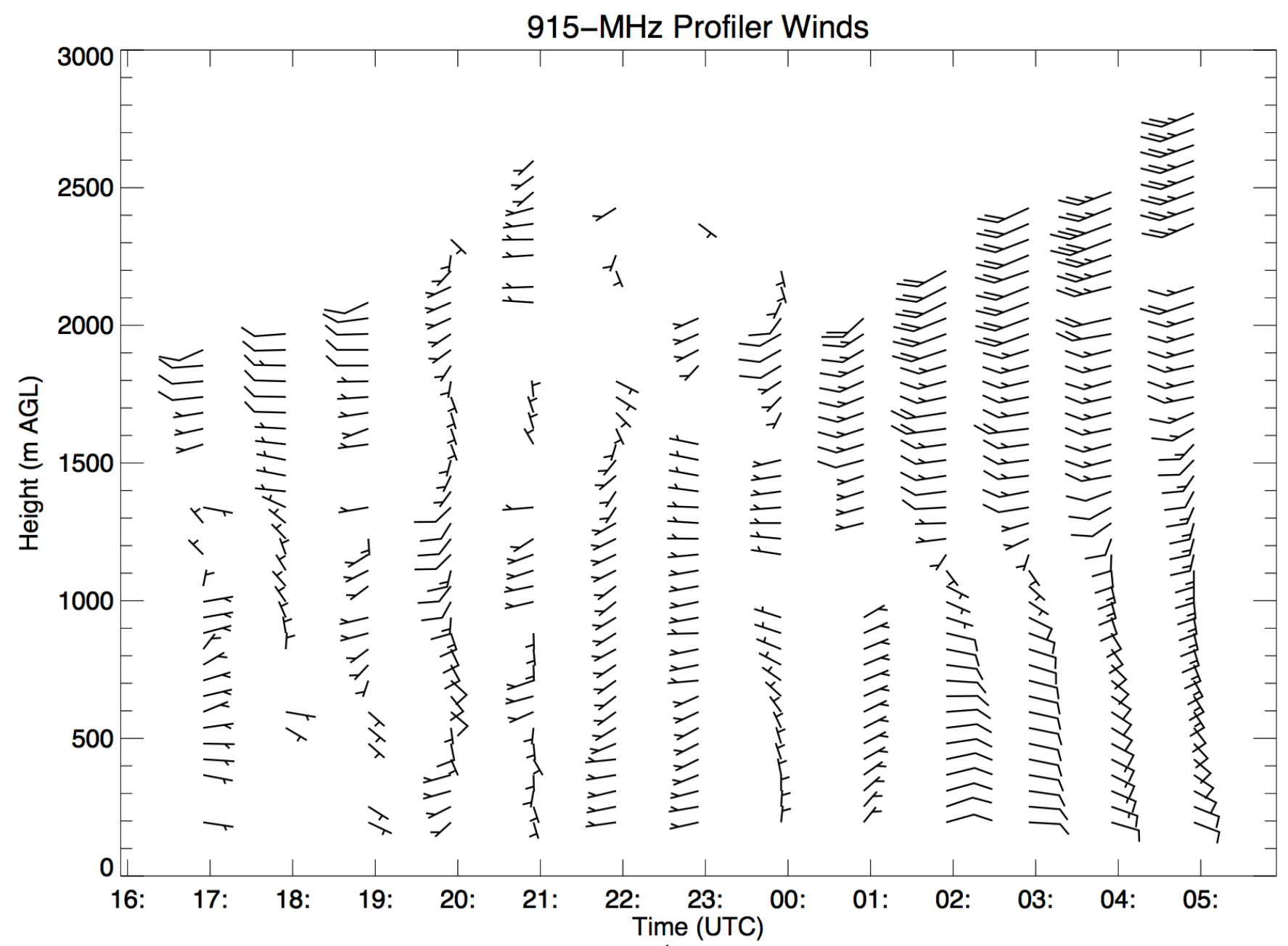

Figure 4. Time-height section of winds (kt; multiply by 0.5144 for $\mathrm{m} \mathrm{s}^{-1}$ ) derived from the $915-\mathrm{MHz}$ wind profiler on the MIPS valid 1700 UTC 4 June 2013 until 0500 UTC 5 June 2013 at 1-h intervals. Wind speed and direction are indicated by wind barbs, where a half barb = 3-7 kt, whole barb $=8-12 \mathrm{kt}$, and pennant $=48-52 \mathrm{kt}$. Missing wind barbs either indicate wind speeds $<3 \mathrm{kt}$ or no data retrieval.

$\geq 5.1 \mathrm{~m} \mathrm{~s}^{-1}(10 \mathrm{kt})$ at and below $1 \mathrm{~km}$ AGL beginning near 0200 UTC (Fig. 4) - likely associated with boundary layer decoupling after sunset. The increased boundary layer wind finally diffused and transported the chaff away from its initial release location by 0430-0500 UTC.

Based on radar (Figs. 3 and 5), ceilometer (Fig. 6), and $915-\mathrm{MHz}$ profiler (Fig. 7) data, the chaff likely was released at low-levels into a convective thermal and transported to the top of the CBL in a process similar to that described in Rowland (1976). The chaff was first observed at $0.5^{\circ}$ elevation from KHTX before appearing at subsequently higher elevations and $Z$ was mostly limited to the $0.5^{\circ}$ and $1.5^{\circ}$ elevation angles for the event duration. $Z_{\max }$ also decreased with height (Fig. 5). Given the average distance from KHTX (approximately $65 \mathrm{~km}$ ), this indicates the largest chaff concentration was generally below $1.0 \mathrm{~km}$ AGL, but high concentrations of chaff approached $2.0 \mathrm{~km}$ AGL (Fig. 5d). Radar (Fig. 5), ceilometer (Fig. 6), and profiler (Fig. 7) data show the chaff extending to the approximate top of the CBL, that grew to near $2.0 \mathrm{~km}$ AGL by 2000 UTC. The ceilometer (Fig. 6) also indicated cloud (saturated black backscatter intensity) during the beginning of the chaff event; however, if chaff was observed by the ceilometer, it is unlikely it could be distinguished from cloud, dust, or other aerosols. Weak $Z(\leq 5 \mathrm{dBZ})$ was occasionally found at $2.5^{\circ}$ elevation (Fig. 5c), indicating some chaff fibers approached and exceeded heights of $3.0 \mathrm{~km}$ AGL as they exited the CBL into the entrainment zone and free atmosphere.

Because KHTX was in volume-coverage-pattern 32 (i.e., a clear-air scanning strategy) at the beginning of the event, the time resolution was too poor to accurately estimate an ascent rate. However, radar (Fig. 3 


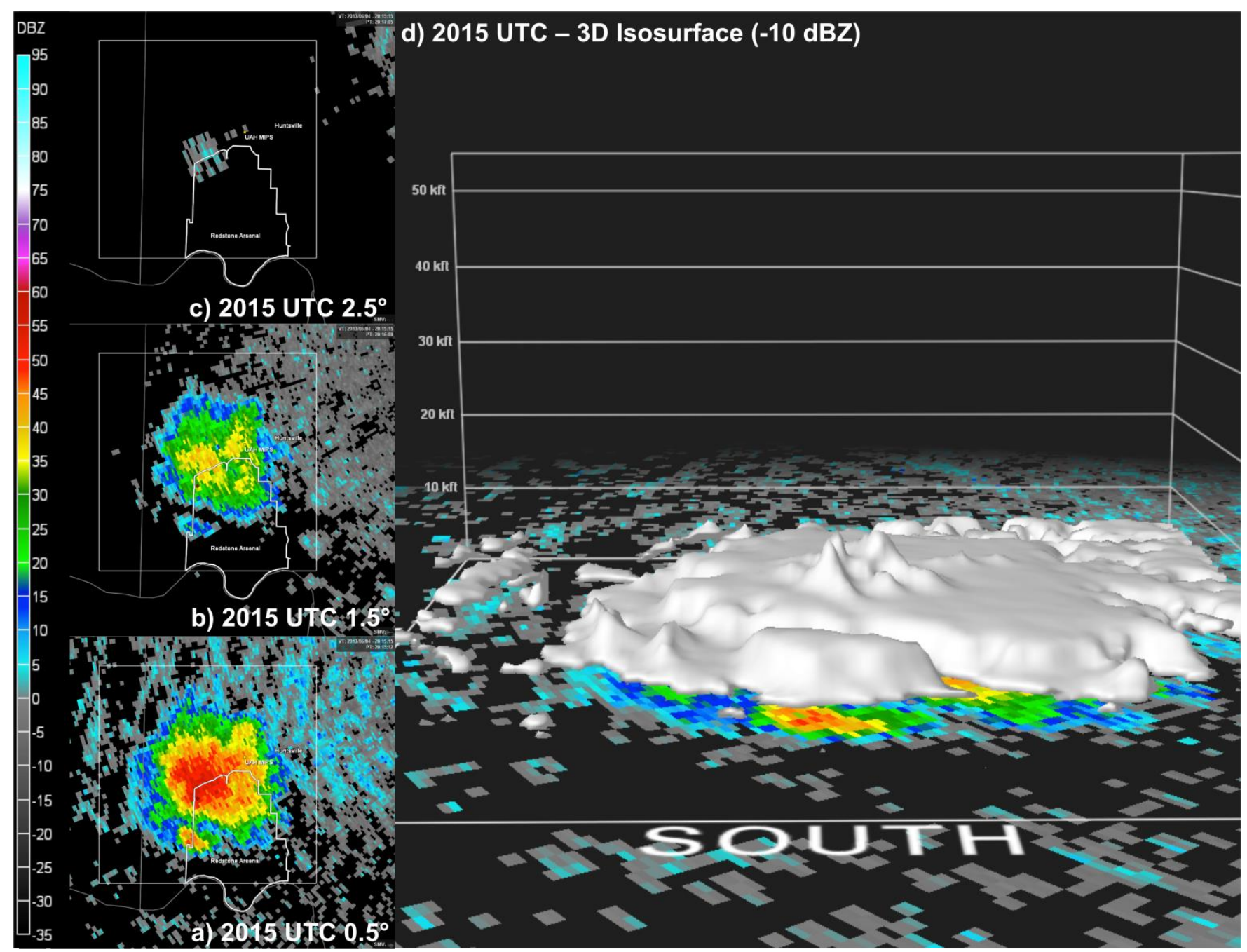

Figure 5. Base reflectivity from KHTX valid 2015 UTC 4 June 2013 at (a) $0.5^{\circ}$, (b) $1.5^{\circ}$, and (c) $2.5^{\circ}$ elevation angles, and (d) the -10 dBZ isosurface. Click image for an animation of panel d) from 1806 UTC 2030 UTC 4 June 2013.

animation) and 915-MHz profiler (Fig. 7) data show that the chaff drifted over the UAH MIPS site at approximately 1940 UTC, thereby allowing for an estimation of vertical air motion and boundary layer evolution from the profiler. By the time of the chaff release, ceilometer (Fig. 6) and profiler (Fig. 7) data indicated the CBL had grown to near $2.0 \mathrm{~km}$ AGL with alternating 2-4 $\mathrm{m} \mathrm{s}^{-1}$ convective updrafts and downdrafts. The chaff was lofted upward from the initial low-level release point by a $3-4-\mathrm{m} \mathrm{s}^{-1}$ convective updraft (Fig. 7) that enabled the chaff to be transported $8 \mathrm{~km}$ to the east-northeast over the UAH MIPS site by west-southwest winds of $\geq 2.6 \mathrm{~m} \mathrm{~s}^{-1}$ ( 5 kt) above $500 \mathrm{~m}$ AGL (Figs. 4 and $5 \mathrm{~d}$ animation). Enhanced SNR values from the $915-\mathrm{MHz}$ profiler (Fig. 7a) after about 1940 UTC extending from near the surface to the top of the boundary layer $(\sim 2.0 \mathrm{~km}$
AGL) indicate that chaff was present throughout the well-mixed CBL. These SNR values are not surprising given the well-mixed boundary layer (Fig. 7b) and that it would only take a few chaff fibers per sample volume to increase SNR owing to the high reflective properties of chaff. The enhanced SNR and $V_{R}$ retrievals indicate that chaff is an excellent tracer of boundary layer motions. This is further shown in the $915-\mathrm{MHz} S W \geq 3 \mathrm{~m} \mathrm{~s}^{-1}$ between 2000 UTC and 2030 UTC, which is indicative of a more turbulent environment associated with the interface between convective updrafts and downdrafts at that time (Figs. $7 \mathrm{~b}$ and $7 \mathrm{c}$ ). Chaff continued to remain lofted to the top of the CBL by $2-4-\mathrm{m} \mathrm{s}^{-1}$ convective updrafts (although weakening) through the early evening (Fig. 7).

Polarimetric properties of the chaff were similar to those described in Zrnić and Ryzhkov (2004). On av- 


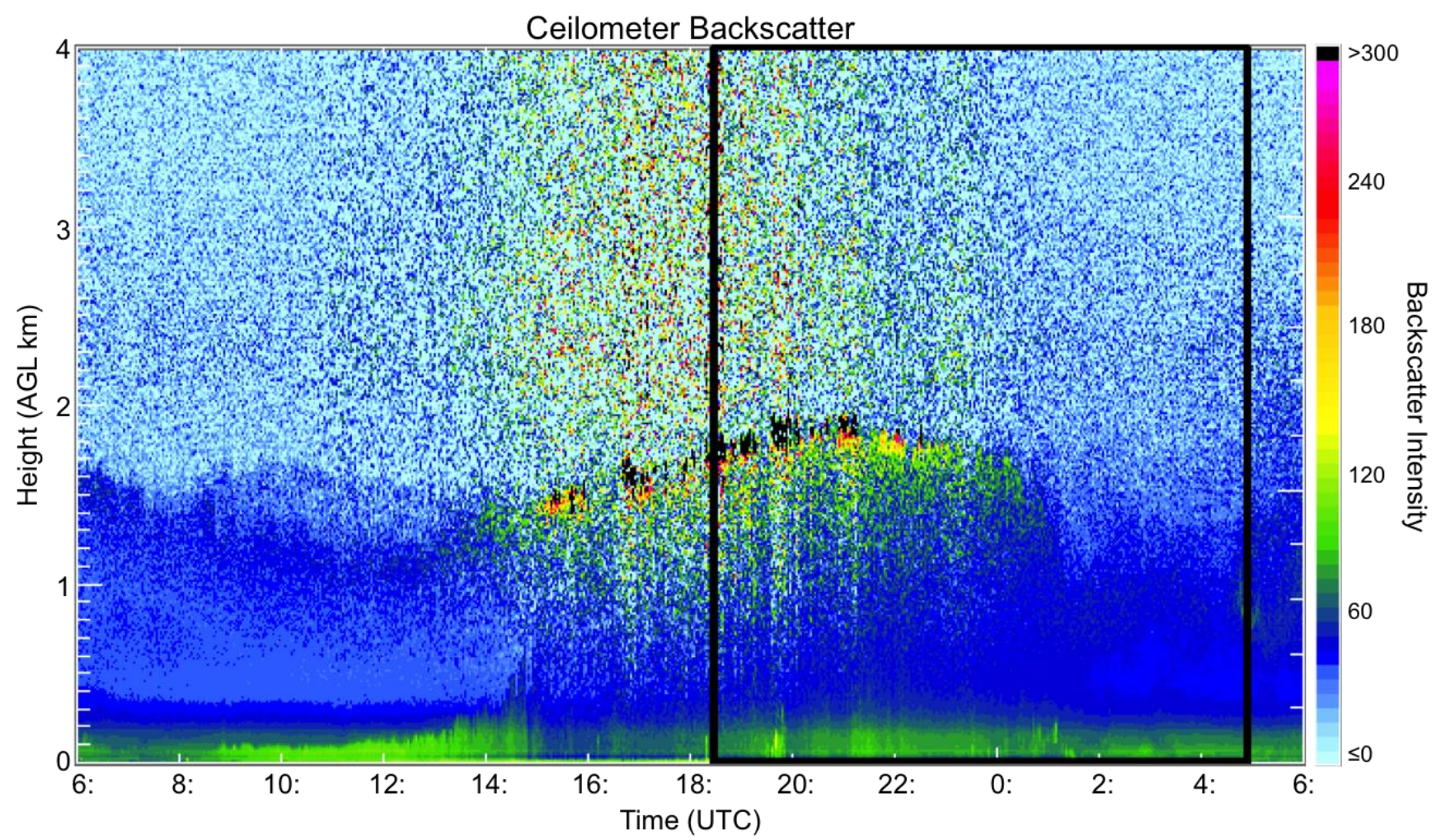

Figure 6. Backscatter intensity from the MIPS lidar ceilometer valid 0600 UTC 4 June 2013 until 0600 UTC 5 June 2013. Increasing intensity indicates an increase in atmospheric aerosol concentration. Backscatter intensity saturated at black indicates cloud. The black box outline represents the time period when chaff was observed by KHTX.

erage, $Z_{\mathrm{DR}}$ ranged from near 0 to $7 \mathrm{~dB}$ within high $Z$ (Fig. 8a), owing to the fact that it is primarily horizontally oriented. However, varying air motions and turbulence will cause the chaff to wobble (i.e., multiple orientations), and thus decrease $Z_{\mathrm{DR}}$. Chaff also may be represented as individual fibers or large clumps of fibers (Fig. 2) in the radar volume. The $\rho_{\text {hv }}$ was low (between 0.2 and 0.6; Fig. 8b), due to the possible random orientations paired with the nonspherical shape of the chaff. The noisiness of the polarimetric data is consistent with low $\rho_{\text {hv }}$ (Bringi and Chandrasekar 2001; Kumjian 2013b).

\section{b. Operational considerations}

\section{1) PUBLIC AND MEDIA INTEREST}

Given the forecast for mostly clear and calm conditions, WFO Huntsville began fielding media inquiries about the unique radar echoes and behavior shortly after they appeared on the KHTX radar data feeds. The first inquiry occurred at 1919 UTC 4 June 2013 via NWS Chat from a local television meteorologist about possible prescribed burns at RSA. Interest in the radar signature continued to intensify on NWS Chat with a flurry of speculation coming from a larger-than-usual variety of local and national media contacts, spotters, and neighboring and distant WFOs. In an attempt to resolve the confusion, WFO Huntsville staff placed a call to contacts at RSA, but no information was available from RSA staff. Speculation centered on chaff (though no one involved had ever seen chaff evolve in such a manner), smoke, insects, and even interference from a damaged power substation (Gore 2013a). Continued public and media inquiries eventually prompted WFO Huntsville to post a story to social media with the limited information available at the time. Despite lacking information, the social media post quickly went viral and was shared on Facebook more than 900 times.

In the days after the chaff event, public and media interest continued rather than waned. Media interview requests came from across the region, anticipating that WFO staff would be able to work with RSA staff in an intragovernmental fashion to solve the mystery. However, contact regarding military exercises is nonsexistent, and the multiple groups, agencies, and commands housed at RSA meant that many RSA employees knew less than WFO meteorologists did. To avoid compro- 


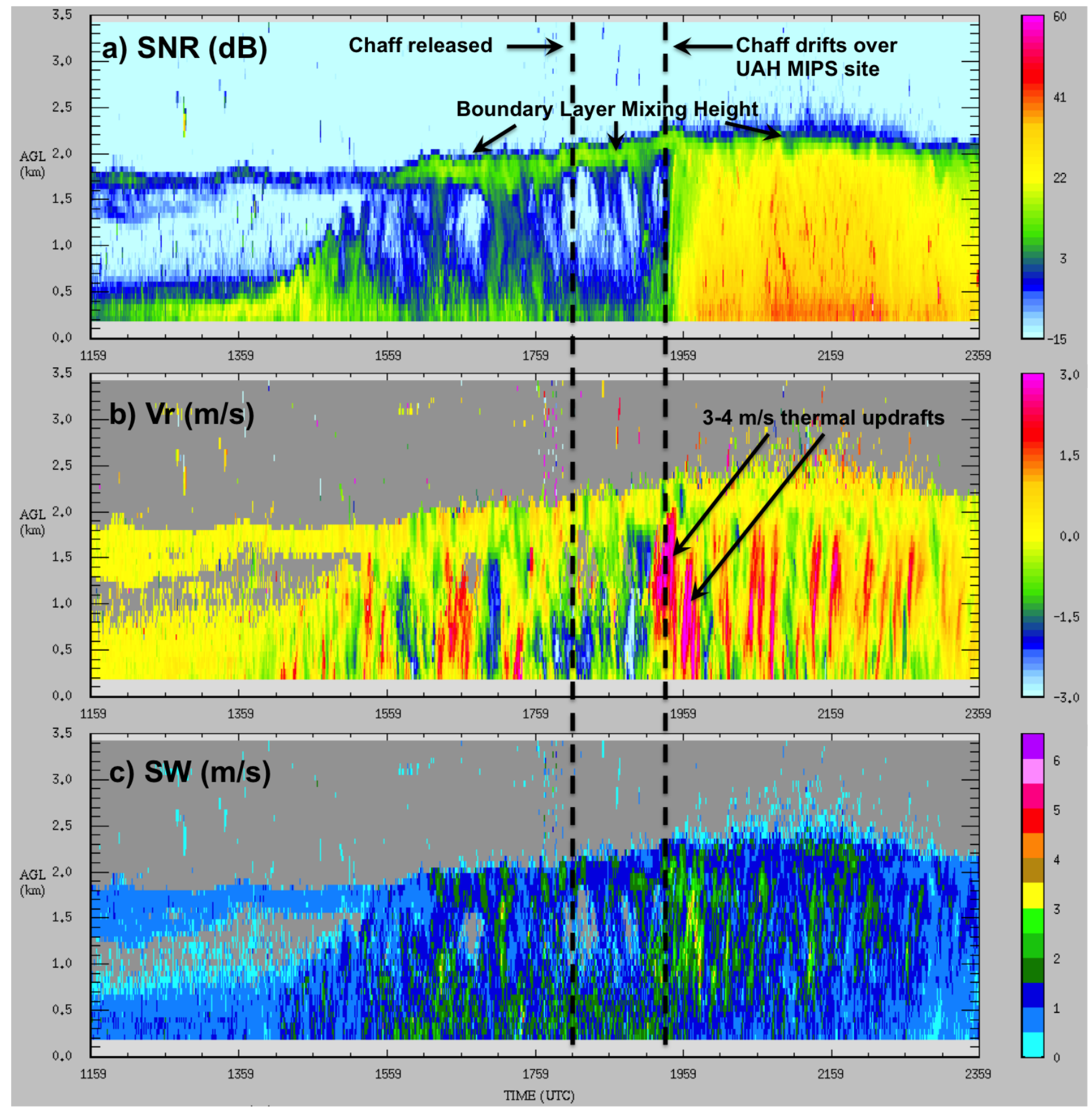

Figure 7. Time-height section of (a) signal-to-noise ratio (SNR, dB), (b) vertical radial velocity $\left(V_{R}, \mathrm{~m} \mathrm{~s}^{-1}\right)$, and (c) spectral width $(S W$, $\mathrm{m}$ $\mathrm{s}^{-1}$ ) from the 915-MHz wind profiler on the MIPS valid 1200 UTC 4 June 2013 until 0000 UTC 5 June 2013 at 1-min resolution.

mising RSA operations, NWS interviews remained focused on facts (e.g., very low $\rho_{\text {hv }}$ confined near the ground suggested that it was biological, chaff, debris, or smoke) and avoided speculation. Media inquiries also were forwarded to experts at UAH for additional interpretation or discussion.
UAH researchers started fielding phone calls, emails, and social media inquiries from local media and weather enthusiasts regarding the radar echo between 1900 and 2000 UTC 4 June 2013. The UAH researchers concluded that the radar echo was most likely from a chaff release because 1) it had polarimetric radar signatures consistent with previous chaff research [such 


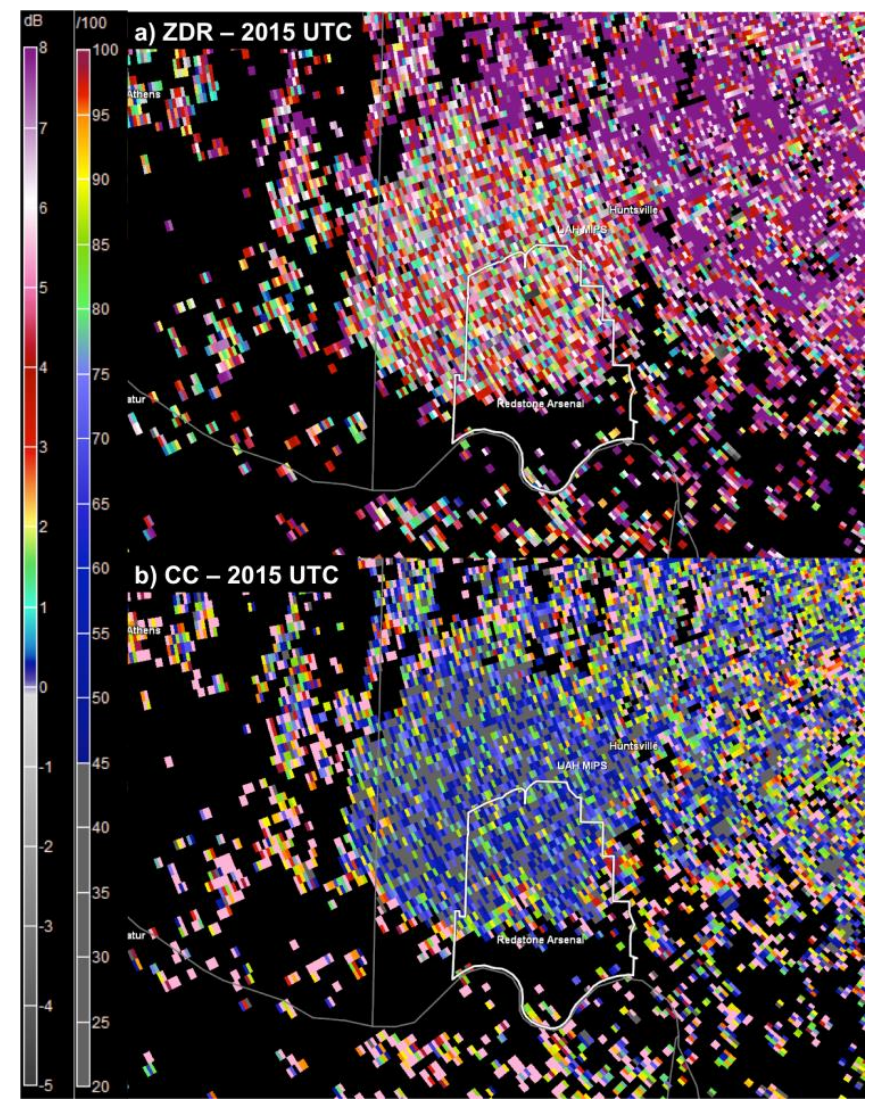

Figure 8. $0.5^{\circ}$ (a) Differential reflectivity $\left(Z_{\mathrm{DR}}, \mathrm{dB}\right)$ and (b) correlation coefficient $\left(\rho_{\text {hv }}\right)$ from KHTX valid 2015 UTC 4 June 2013.

as Zrnić and Ryzhkov (2004)] and 2) the point source emanated from within the RSA boundary. By midafternoon 4 June 2013, UAH researchers considered the "radar blob" had been explained and the mystery solved, although they could not get confirmation from RSA at that time. However, the chaff explanation was not accepted by some individuals, so to confirm that chaff was the culprit, authors Wade and Murphy traveled to near the point source location of the radar blob (albeit outside the RSA boundary) during the morning of 5 June 2013 and found numerous clumps of chaff, pictured in Fig. 2. On 6 June 2013, RSA finally issued a statement confirming the chaff release and that the type of chaff was RR-188 (Gore 2013b).

\section{2) RADAR PRECIPITATION ALGORITHMS}

Because of the intense, long-lasting nature of the chaff echoes, KHTX legacy precipitation algorithms indicated significant rainfall artifacts underneath the chaff plume over the span of $4 \mathrm{~h}$. By 2240 UTC 4 June 2013, 1-h precipitation artifacts reached $5.1 \mathrm{~cm} \mathrm{~h}^{-1}(2$ in $\mathrm{h}^{-1}$; Fig. 9a) while the storm-total precipitation arti-

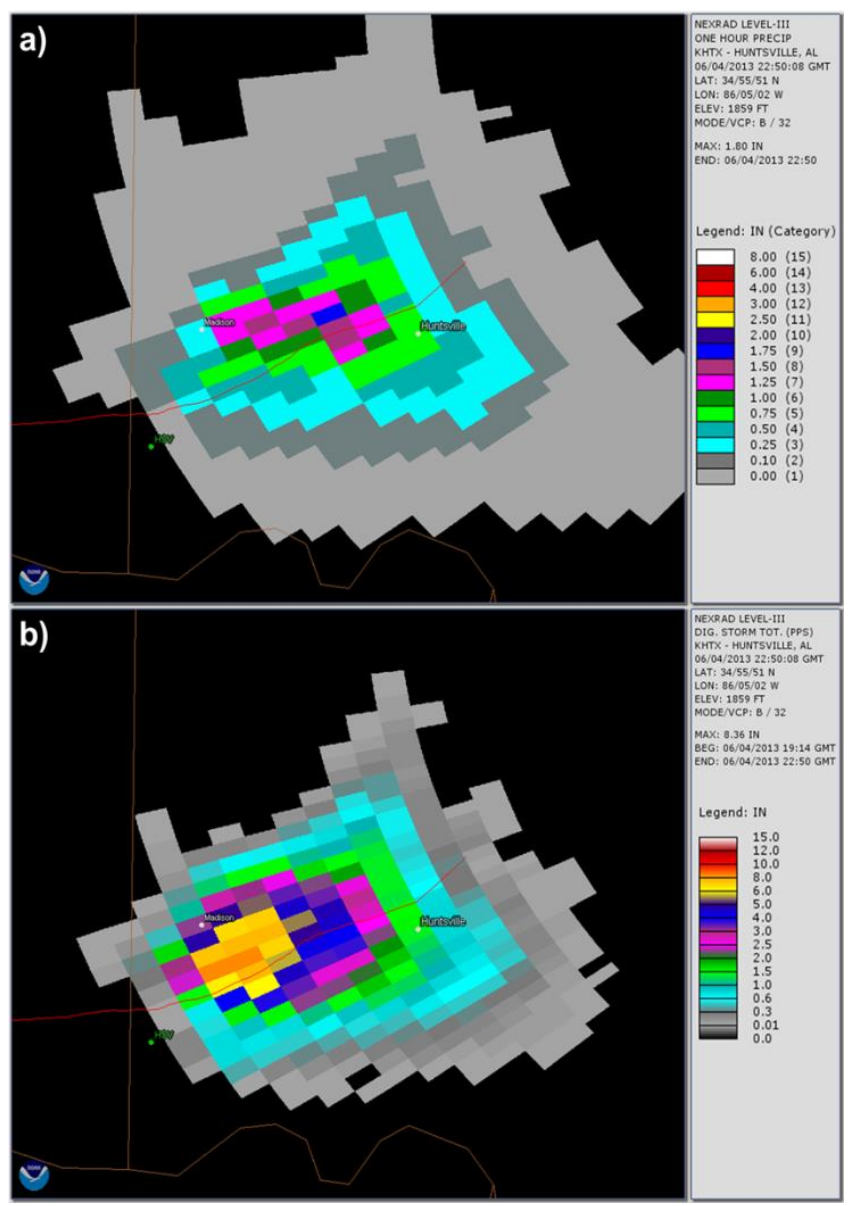

Figure 9. (a) Legacy 1-h precipitation algorithm output and (b) digital storm-total precipitation output from KHTX, valid 2250 UTC 4 June 2013 . Units are in (multiply by 2.54 for $\mathrm{cm}$ ).

facts exceeded $20.3 \mathrm{~cm}$ ( $8 \mathrm{in}$ ) in the southern portion of Madison, Alabama, just north of Interstate 565 (Fig. $9 b$ ). After 2250 UTC, WFO staff employed methods to filter the chaff from further contaminating the accumulated precipitation by manually resetting the legacy accumulations to zero. As designed, dual-polarization precipitation estimates successfully filtered the chaff throughout the event due to the low $\rho_{\mathrm{hv}}$ and correctly did not accumulate any precipitation. However, many meteorological products both inside and outside of the NWS still use legacy precipitation output for a variety of purposes. In some cases, the spurious precipitation artifacts continued to affect these products. For example, the NWS national precipitation estimates web page in use at the time indicated a bulls-eye of abovenormal precipitation embedded within an area of below-normal precipitation for the month of June in the same location as the chaff (Fig. 10a). The spurious precipitation artifacts for June 2013 have since been removed (Fig. 10b). 

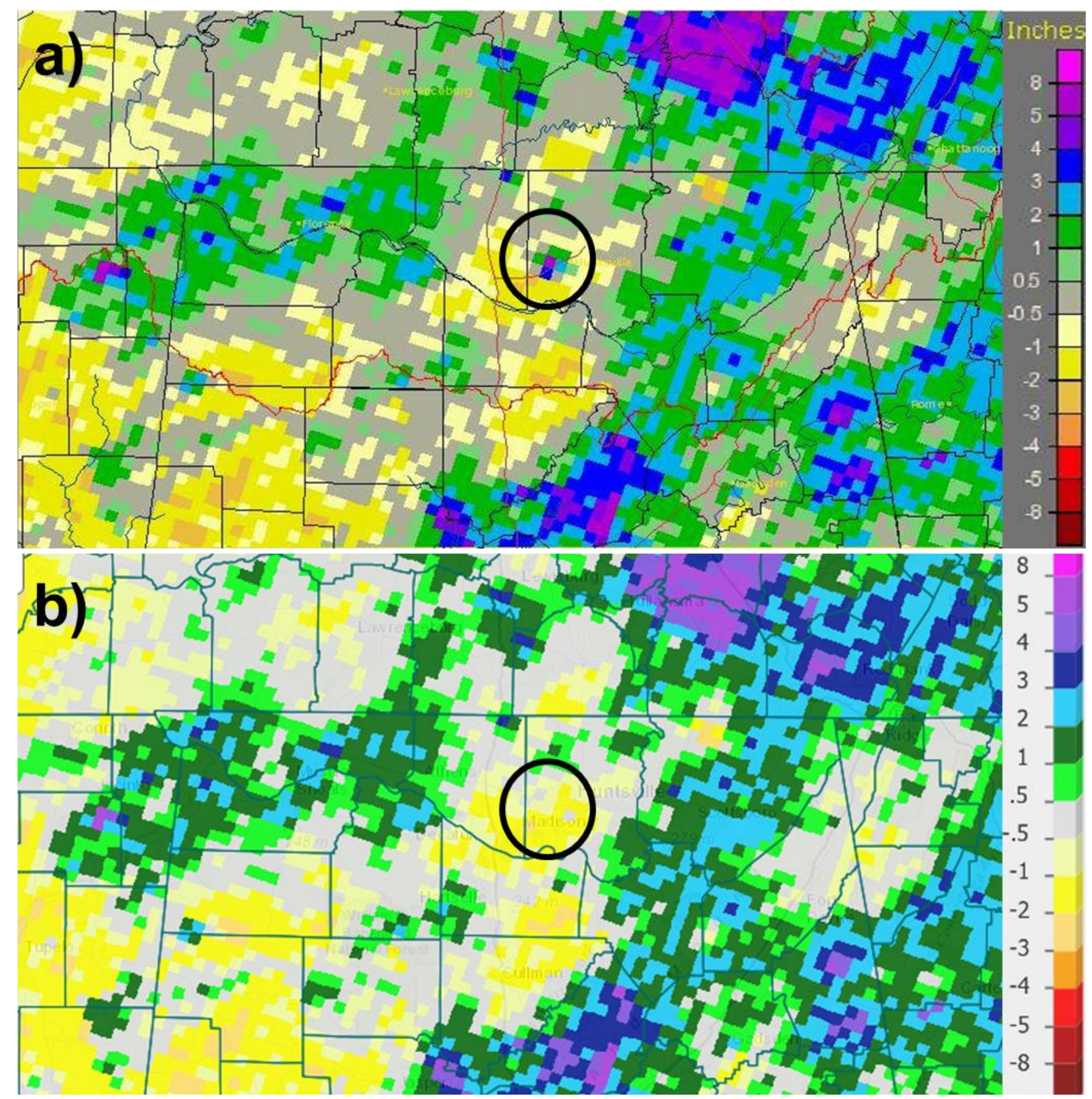

Figure 10. NWS precipitation estimate mosaic, 30-day departure from normal, valid 1 July 2013: (a) including estimates adversely affected by the chaff release (black circle) on 4 June 2013; and (b) after the spurious precipitation was removed.

\section{Conclusions}

The 4 June 2013 chaff release in northern Alabama shared similarities to other radar-observed chaff events, but also was unusual in several aspects. The chaff was released at a low altitude (between 0.8 and 1 $\mathrm{km}$ AGL according to radar) during a mostly clear day with light and variable boundary layer winds. It was first observed at $0.5^{\circ}$ elevation, but quickly rose to the top of the CBL, indicating a release in or near a convective thermal. The weak winds led to limited transport and diffusion of the chaff, keeping concentrations high near the initial release location. As a result, radar $Z$ exceeded $50 \mathrm{dBZ}$ for several hours, and occasionally surpassed $60 \mathrm{dBZ}$. Its radar appearance resembled that of a strong airmass thunderstorm when only viewed at 
$0.5^{\circ}$ elevation scan. The radar $Z$ evolution at $0.5^{\circ}$ elevation also resembled an airmass thunderstorm evolution with the second chaff release resembling a gust front along the southern flank resulting in convective redevelopment. The chaff also remained in the atmosphere well after its initial release, maintaining a radar echo on KHTX for approximately $10 \mathrm{~h}$. It was not until the background wind increased and changed directions that the chaff finally began to diffuse and transport away from northern Alabama.

The appearance of the chaff created a challenging media relations environment for WFO Huntsville, as there was a need to balance scientific expertise and transparency with potential military operations impacts. The chaff also managed to produce artifacts in the legacy WSR-88D precipitation algorithms, which accumulated more than $20.3 \mathrm{~cm}$ ( 8 in) of precipitation associated with the chaff plume before WFO meteorologists manually intervened. This case highlights the need for forecasters to maintain high levels of situational awareness for unexpected radar echoes-where they are located and originate from, what all available data are showing (especially polarimetric radar products), how they evolve, and within what meteorological environment they exist.

Acknowledgments. This research was funded in part by the School of Science at the University of Louisiana at Monroe and the Department of Atmospheric Science at the University of Alabama in Huntsville. Use of the MIPS instruments occurred during the ABIDE-III field project supported by the National Science Foundation under grant AGS-1110622. We acknowledge Paul Schlatter and two anonymous reviewers for providing comments that greatly improved the original manuscript.

\section{REFERENCES}

Berkowitz, D. S., J. A. Schultz, S. Vasiloff, K. L. Elmore, C. D. Payne, and J. B. Boettcher, 2013: Status of dualpol QPE in the WSR-88D network. Preprints, 27th Conference on Hydrology, Austin, TX, Amer. Meteor. Soc., 2.2. [Available online at ams.confex.com/ams/ 93Annual/webprogram/Paper221525.html.]

Brandt, B., and D. V. Atkin, 1998: Chaff in the vicinity of thunderstorms in southern California on 6 June 1997. NOAA/NWS Western Region Tech. Attach. No. 98-04, 7 pp. [Available online at www.wrh.noaa.gov/media/ wrh/online_publications/TAs/ta9804.pdf.]

Bringi, V. N., and V. Chandrasekar, 2001: Polarimetric Doppler Weather Radar: Principles and Applications. Cambridge University Press, 636 pp.
Cornman, L. B., R. K. Goodrich, C. S. Morse, and W. L. Ecklund, 1998: A fuzzy logic method for improved moment estimation from Doppler spectra. J. Atmos. Oceanic Technol., 15, 1287-1305, CrossRef.

Eresmaa, N., J. Härkönen, S. M. Joffre, D. M. Schultz, A. Karppinen, and J. Kukkonen, 2012: A three-step method for estimating the mixing height using ceilometer data from the Helsinki testbed. J. Appl. Meteor. Climatol., 51, 2172-2187, CrossRef.

Gattis, P., 2013: Radar chaff over Redstone Arsenal unusual, lingered in atmosphere 10 hours. Huntsville Times, 6 June 2013. [Available online at blog.al.com/ breaking/2013/06/radar_chaff_over_redstone_arse.html.]

Gore, L., 2013a: So why is radar showing a mysterious blob above Redstone Arsenal? No one seems to know. Huntsville Times, 4 June 2013. [Available online at blog.al.com/breaking/2013/06/so_why_was_radar_sho wing_a mys.html.]

, 2013b: Redstone Arsenal blob mystery solved Officials say radar anomaly caused by chaff from testing. Huntsville Times, 6 June 2013. [Available online at blog.al.com/breaking/2013/06/redstone _arsenal_blob_mystery.html.]

Han, H-Y., B. H. Heo, S. H. Jung, G. W. Lee, C. H. You, and J. H. Lee, 2011: Elimination of chaff echoes in reflectivity mosaic of operational weather radar network using infrared satellite data. Preprints, 35th Conference on Radar Meteorology, Pittsburgh, PA, Amer. Meteor. Soc., 138. [Available online at ams.confex.com/ams/35Radar/webprogram/Paper19163 1.html.]

Karan, H., and K. Knupp, 2009: Radar and profiler analysis of colliding boundaries: A case study. Mon. Wea. Rev., 137, 2203-2222, CrossRef.

Kumjian, M. R., 2013a: Principles and applications of dualpolarization weather radar. Part I: Description of the polarimetric radar variables. J. Operational Meteor., 1 (19), 226-242, CrossRef.

2013b: Principles and applications of dual-polarization weather radar. Part III: Artifacts. J. Operational Meteor., 1 (21), 265-274, CrossRef.

Morse, C. S., R. K. Goodrich, and L. B. Cornman, 2002: The NIMA method for improved moment estimation from Doppler spectra. J. Atmos. Oceanic Technol., 19, 274-295, CrossRef.

Roop, L., 2013: Redstone radar blob: 'Whatever it was' versus what we know it wasn't. Huntsville Times, 5 June 2013. [Available online at blog.al.com/breaking/ 2013/06/redstone radar_blob whatever_i.html.]

Rowland, J. R., 1976: Clear air convective behavior revealed by radar chaff. J. Appl. Meteor, 15, 521-526, CrossRef.

USAF, 1997: Environmental effects of self-protection chaff and flares. Final Report, Headquarters Air Combat Command, Langley Air Force Base, Virginia, 241 pp. 
[Available online at www.acc.af.mil/shared/media/ document/AFD-070807-011.pdf.]

, 2010: Characteristics of chaff. Appendix C, Powder River Training Complex EIS, 14 pp. [Available online at www.ellsworth.af.mil/shared/media/document/AFD121022-061.pdf.]

Vasiloff, S., and M. Struthwolf, 1997: Chaff mixed with radar weather echoes. NOAA/NWS Western Region Tech. Attach. No. 97-02, 10 pp. [Available online at
www.wrh.noaa.gov/media/wrh/online_publications/TA s/ta9702.pdf.]

WHNT, 2013: 'Chaff' new theory on mystery radar blob. News 19, 5 June 2013. [Available online at whnt.com/ 2013/06/05/chaff-new-theory-on-mystery-radar-blob/.]

Zrnić, D. S., and A. V. Ryzhkov, 2004: Polarimetric properties of chaff. J. Atmos. Oceanic Technol., 21, 10171024, CrossRef. 